\title{
Not All Uncertainty Is Treated Equally: Information Search Under Social and Nonsocial Uncertainty
}

\author{
Nadine Fleischhut ${ }^{\mathrm{a}}$, Florian M. Artinger ${ }^{\mathrm{a}, \mathrm{b}, \mathrm{c}}$, Sebastian Olschewski ${ }^{\mathrm{d}, \mathrm{e}}$, and \\ Ralph Hertwig ${ }^{\mathrm{a}}$ \\ ${ }^{a}$ Center for Adaptive Rationality, Max Planck Institute for Human Development, Germany \\ ${ }^{\mathrm{b}}$ Berlin International University of Applied Sciences, Germany \\ c Simply Rational - The Decision Institute, Germany \\ ${ }^{\mathrm{d}}$ Department of Psychology, University of Basel, Switzerland \\ ${ }^{\mathrm{e}}$ Warwick Business School, University of Warwick, UK
}

\begin{tabular}{ll} 
& \multicolumn{1}{c}{ Author Note } \\
Nadine Fleischhut & https://orcid.org/0000-0002-6807-3455 \\
Florian M. Artinger & https://orcid.org/0000-0001-9572-2329 \\
Sebastian Olschewksi & https://orcid.org/0000-0001-9371-1597 \\
Ralph Hertwig & https://orcid.org/0000-0002-9908-9556
\end{tabular}

Florian Artinger is now at the Berlin International University of Applied Sciences, Germany. There are no conflicts of interest to disclose. Part of Experiment 1 was presented at the 2014 meeting of the Cognitive Science Society in Quebec, Canada, and appeared in the conference proceedings.

Correspondence concerning this article should be sent to Nadine Fleischhut, Center for Adaptive Rationality, Max Planck Institute for Human Development, Lentzeallee 94, 14195 Berlin, Germany. E-mail: fleischhut@mpib-berlin.mpg.de or nfleischhut@gmail.com 


\begin{abstract}
The social world is often portrayed as being less predictable and more uncertain than the nonsocial world. People may therefore feel the need to search more for information before making a choice. However, we suggest that cognitive tools such as social projection and normbased expectation may help people to predict others' behaviors in the social world and thus serve as a substitute for information search. We argue that in situations where the environment affords this possibility, social uncertainty may in fact trigger less search than nonsocial uncertainty. Consistent with our expectations, findings from two experiments showed that participants sampled considerably less and systematically differently in a mini-ultimatum game (mUG; social uncertainty) than in structurally identical lotteries (nonsocial uncertainty). Even selfish individuals sensitive to the risk of rejection did not sample more than others, let alone as much as people in lotteries. Raising the stakes strongly increased sampling effort in lotteries but not in the social game. When evaluating risks based on outcomes alone, participants also anticipated searching less in mUGs than in lotteries, indicating that they were aware of norm-based regularities in social worlds and that they exploited those regularities to guide their expectations. The findings highlight that the structure of social environments can enable decision makers to use cognitive tools to navigate uncertainty without needing to invest in extensive search.
\end{abstract}

Keywords: information search, social uncertainty, decisions from experience, risky choice, social preference, ultimatum game 


\section{Not All Uncertainty Is Treated Equally: Information Search Under Social and Nonsocial Uncertainty}

The social world is often portrayed as less predictable and more uncertain than the nonsocial world (e.g., Byrne \& Whiten, 1988; Hertwig \& Herzog, 2009). People’s goals, preferences, and behavioral strategies vary widely. The human ability to generate beliefs about others' behaviors, beliefs about others' beliefs about one's own behavior, and so on, can quickly render social interactions intractable (e.g., Fiske \& Taylor, 1984; Humphrey, 1988; Sterelny, 2003). Moral sentiments, emotions, and irrational impulses complicate the situation further (Hertwig \& Volz, 2013; Volz \& Hertwig, 2016). Moreover, social behaviors interact with the structure of social environments, meaning that the same person may behave altruistically in one situation but selfishly in another (e.g., Blanco, Engelmann, \& Normann, 2011; Olschewski, Dietsch, \& Ludvig, 2019). Relative to the social world, nature or chance may appear tamer, less uncertain, and more predictable. But does the social world thus also trigger more information search than the nonsocial world? In this article, we demonstrate that this is not necessarily the case. On the contrary, the social world affords people with cognitive tools that may help to predict others' behaviors and thus serve as a substitute for information search. Here, we conduct two experiments to test the hypothesis that people therefore in fact sample less under social uncertainty than in games against chance.

Two such cognitive tools tailored to the social world are projection of one's own behavior and expectations based on social norms. In social projection, people assume that others will act like they would themselves. Such projection need not be egocentric, self-serving, or irrational but can be Bayesian inductive reasoning at its best (Denrell \& Le Mens, 2007; Krueger, DiDonato, \& Freestone, 2012). If based on existing statistical associations between one's own and others' choices, social projection can even be highly accurate (Krueger et al., 2012). In bargaining situations, for example, individuals can enlist their own response to an offer or allocation (i.e., "Would I accept or reject?") to evaluate the risk of rejection without the need for extensive exploration (see, e.g., Mill \& Theelen, 2019, for social projection in cooperation). In contrast, norm-based expectations can reduce uncertainty even without social projection. Social norms enable people to generate expectations about others' behavior, whether those norms are descriptive (what most people do) or injunctive (what most people ought to do; Cialdini, Kallgren, $\&$ Reno, 1991). Wherever norms such as equity, cooperation, or reciprocity operate, they not only 
create 'focal points' (Bacharach \& Bernasconi, 1997) that allow individuals to coordinate behavior under uncertainty (e.g., fair divisions in bargaining; Bicchieri \& Chavez, 2009; Carpenter, 2003; Rand et al., 2014), but also imply regularities beyond focal points. If one believes a norm to hold in a bargaining situation, the degree of deviation from that norm is a good predictor of the risk of an allocation being rejected. As a consequence, the risk can again simply be read off the proposed allocation without extensive exploration of how people might respond to it. In either case, knowledge of the possible outcomes suffices to infer the risk of rejection. In situations where uncertainty results from chance mechanisms, in contrast, decision makers need to explore both outcomes and their probabilities in order to form expectations.

The possibility of harnessing cognitive tools to cope with social uncertainty thus implies a qualitative difference between social games (where the source of uncertainty resides in the behavior of others) and games against chance (where it resides in some random device). We propose that this difference is reflected in the efforts people make to explore the environment before making a decision - in other words, in the extent of sampling. Less sampling signals that people feel less need to explore - and, we propose, a greater likelihood that cognitive tools have been harnessed to inform their choices under uncertainty.

To test this hypothesis, we investigated how much people sample in situations involving social uncertainty relative to situations where uncertainty results from chance. Specifically, we adapted one of the most frequently studied social games, the ultimatum game (Güth, Schmittberger, \& Schwarze, 1982), as a paradigm of social uncertainty. In the ultimatum game, one person (proposer) divides an amount of money between themself and another person (responder). The responder can accept or reject the offer. In the variant we used, the proposer chooses between two possible divisions (mini-ultimatum game: mUG; Bolton \& Zwick, 1995). If the responder accepts, the division is implemented. If the responder rejects, both receive nothing. The proposer thus faces social uncertainty: Which offer is the responder more likely to accept? By giving the responder the opportunity to reject offers, the ultimatum game invokes social norms on how money ought to be shared. At the same time, various other norms and motivations may apply: Is the responder motivated by self-interest, meaning that they will accept any nonzero offer? Or are they motivated by equality concerns, meaning that they will reject all unequal offers? Would the responder accept an offer that maximizes social welfare - that is, the offer adding up to the larger overall amount-irrespective of how it is allocated? Because the 
interaction is anonymous, the proposer cannot draw on any knowledge about the responder. One way to reduce the risk of rejection is to be more generous than self-interest proscribes. In fact, proposers often offer up to $40 \%-50 \%$ of the monetary pie. However, there is considerable heterogeneity in offers, indicating that proposers have different expectations about what responders will find acceptable (e.g., Fehr \& Schmidt, 1999; Harrison \& McCabe, 1996).

Proposers may form these expectations by applying cognitive tools such as inference from social norms or projection of their own behavior. Here, we also gave proposers the opportunity to sample information on how often allocations had been accepted or rejected in the past before making their offer to a responder who could accept or reject it. They could sample at no cost, in any sequence, and as many times as they wanted (decision from experience; Hertwig \& Erev, 2009). We compared proposers' sampling behavior with that of solitary players in lotteries that had identical probabilities and payoffs. In lotteries, however, projection and social norms cannot be employed to evaluate risk.

\section{Overview of Experiments}

We ran two experiments to test seven implications of the hypothesis that people use cognitive tools as a substitute for sampling to reduce social uncertainty. In both experiments, participants sampled and made several decisions without feedback (Table 1), either as a proposer choosing between two allocations or as a solitary player choosing between two lotteries. Experiment 1 tested whether individuals in mUGs sample less than those in lotteries, the relation of sampling effort to social motives and risk attitudes, and whether choices in mUGs and lotteries are similar despite different ways to assess the risk. Experiment 2 tested whether differences in sampling behavior hold under higher incentives, with anticipated rather than actual sampling, and explored an alternative hypothesis as to why choices are similar in both conditions. In addition, it examined whether the results of Experiment 1 were replicable under stricter conditions.

Both experiments were run using z-Tree (Fischbacher, 2007) with a customized sampling implementation.

\section{Experiment 1}

Our first experiment examined four implications of the hypothesis that people use cognitive tools as a substitute for sampling to cope with social uncertainty. 


\section{Does sampling behavior differ between $\mathrm{mUG}$ and lotteries?}

The possibility of using cognitive tools to reduce social uncertainty implies differences in how much people sample, how they sample, and when they stop. If such tools are used, knowledge of the possible outcomes suffices to evaluate the risk; there is no need to sample to estimate their likelihood. We therefore expected participants to sample less in mUGs than in isomorphic lotteries. In mUGs, they should sample only to learn about the outcomes and stop once all outcomes have been experienced. In lotteries, in contrast, they should sample more, and more systematically, to reduce uncertainty and accurately estimate the frequency of outcomes for each option separately (Hertwig \& Pleskac, 2010; Hills \& Hertwig, 2010).

\section{Do even risk-sensitive selfish individuals sample less in mUGs than players in lotteries?}

Individuals in social environments are driven by diverse social motives. For some, prosocial concerns such as equity, social welfare, or altruism are paramount; others are driven by self-interest. Selfish individuals in mUGs share the motive of players in lotteries: to maximize their outcomes. To this end, they need to carefully gauge the risk of rejection (Artinger, Exadaktylos, Koppel, \& Sääksvuori, 2014)—knowledge that may be less important for those with prosocial concerns by simple virtue of the fact that their offers are more attractive to the recipient and thus less likely to be rejected.

Yet selfish individuals may gauge the risk of rejection in two quite different ways: On the one hand, a selfish "rational" individual ("homo economicus") will not reject any offer above zero and will conclude, by virtue of social projection, that others will act in the same way. Even if this conclusion is wrong, such selfish individuals will see no reason to sample the empirical risk of rejection. Knowledge of the possible outcomes suffices to form an expectation.

On the other hand, (some) selfish individuals may be well aware of the risk of low offers being rejected. Being sensitive to this risk, these individuals may have good reason to sample the empirical risk of rejection, thus avoiding rejection and loss of income. We might therefore expect this risk-sensitive group to treat the social interaction like a lottery (Costa-Gomes, Crawford, \& Broseta, 2001) and to sample as much as individuals in the lottery context. Alternatively, however, even this group could base their expectations on social norms. In this case, knowledge of the possible outcomes again suffices to form expectations about the risks of rejection. As knowledge about risk is particularly crucial for risk-sensitive selfish individuals, findings showing that even 
they sample less in mUGs than players in lotteries would further support the hypothesis that people substitute sampling by cognitive tools to cope with social uncertainty.

\section{Are risk attitude and sampling effort decoupled?}

Sampling effort in lotteries may likely be related to individual risk attitudes (Wulff, Hills, \& Hertwig, 2015): The more risk-averse somebody is, the more they may feel a need to reduce their sense of uncertainty by sampling. Should cognitive tools help to reduce social uncertainty, however, risk attitude may be decoupled from sampling effort in mUGs.

\section{Do choices in mUGs and lotteries converge?}

There is reason to expect choices in $\mathrm{mUG}$ and lotteries to be rather similar even if individuals in mUGs sample less than individuals in lotteries. If social projection and norm-based expectations enable individuals in mUGs to sufficiently estimate the risk of an option even without extensive sampling, their risk perception need not differ substantially from individuals' risk perception in lotteries. Despite different ways of assessing the risk of the situation, choices may thus in the aggregate converge in both conditions.

\section{Methods}

\section{Participants}

Eighty-eight students (40 women, 48 men; $M=25.11$ years) were recruited from the Technical University of Berlin and randomly assigned to either the mUG or the lottery condition in one of four sessions ( $n=20-24$ participants per session). The number of participants was determined before data collection based on previous research on decisions from experience (e.g., Hau, Pleskac, Kiefer, \& Hertwig, 2008) and set at two sessions with 24 participants each per condition. A sample size of 48 per condition is sufficient to detect the effect observed with a power of .9 (post-hoc power analysis, one-tailed Mann-Whitney $U$ test with $r=.64$ and $\alpha=.05$ ).

The Ethics Committee of the Max Planck Institute for Human Development approved the study, and all participants gave informed consent.

\section{Experimental materials}

Each allocation in the mUG specifies two outcomes: the proposer's and the responder's payoff. To offer realistic feedback on past responder behavior, we ran a preliminary study with 24 participants drawn from the same population and collected acceptance and rejection rates (rounded in steps of 5\%) for 43 mUGs. From this set, we selected $12 \mathrm{mUGs}$ with systematically varying probabilities of acceptance (or, by extension, risks of rejection): In each mUG, one option 
was a relatively "safe" allocation, accepted by at least $90 \%$ of participants. The other was a relatively "risky" allocation, for which the probability of acceptance decreased systematically from $80 \%$ to $20 \%$ across the 12 games (Table 1 ; note that situations no. 1, 9, and 10 were not tested in Experiment 1).

Table 1

Choice Situations Employed in Experiments 1 and 2

\begin{tabular}{|c|c|c|c|c|c|c|c|c|}
\hline \multirow{3}{*}{$\begin{array}{l}\text { Choice } \\
\text { situation }\end{array}$} & \multicolumn{7}{|c|}{ Options } & \multirow{3}{*}{$\begin{array}{l}\text { Main beneficiary } \\
\text { of safe option }\end{array}$} \\
\hline & \multicolumn{2}{|c|}{ Risky option } & \multicolumn{2}{|c|}{ Safe option } & \multirow{2}{*}{$\begin{array}{l}\text { Risky option } \\
p \text { (accept) }\end{array}$} & \multirow{2}{*}{$\begin{array}{l}\text { Safe option } \\
p \text { (accept) }\end{array}$} & \multirow{2}{*}{$\begin{array}{l}\mathrm{EV} \\
\text { ratio }\end{array}$} & \\
\hline & own & responder & own & responder & & & & \\
\hline $1^{+}$ & 60 & 30 & 50 & 50 & 95 & 100 & 1.14 & Both equally \\
\hline 2 & 55 & 45 & 50 & 50 & 80 & 100 & 0.88 & Both equally \\
\hline 3 & 80 & 20 & 40 & 40 & 80 & 100 & 1.60 & Both equally \\
\hline 4 & 70 & 20 & 40 & 40 & 80 & 100 & 1.4 & Both equally \\
\hline 5 & 80 & 20 & 60 & 40 & 80 & 100 & 1.07 & Proposer \\
\hline 6 & 40 & 20 & 20 & 80 & 75 & 90 & 1.67 & Responder \\
\hline 7 & 70 & 30 & 35 & 35 & 70 & 90 & 1.56 & Both equally \\
\hline 8 & 65 & 35 & 55 & 45 & 70 & 90 & 0.92 & Proposer \\
\hline $9^{+}$ & 75 & 25 & 70 & 30 & 70 & 85 & 0.88 & Proposer \\
\hline $10^{+}$ & 70 & 30 & 55 & 45 & 60 & 100 & 0.76 & Proposer \\
\hline 11 & 80 & 20 & 50 & 30 & 55 & 90 & 0.98 & Proposer \\
\hline 12 & 50 & 15 & 25 & 50 & 55 & 95 & 1.16 & Responder \\
\hline 13 & 60 & 5 & 25 & 60 & 25 & 95 & 0.63 & Responder \\
\hline 14 & 110 & 5 & 30 & 65 & 25 & 95 & 0.96 & Responder \\
\hline 15 & 120 & 0 & 25 & 45 & 20 & 95 & 1.01 & Responder \\
\hline
\end{tabular}

Note: The left-hand columns show the outcomes of the risky and safe option for the proposer (own) and the responder. For lotteries, only the "own" outcome is relevant. $P($ accept) is the probability of receiving the nonzero outcome for the respective option (i.e., the responder accepting the allocation in the mUGs); corresponding probabilities for rejection and zero

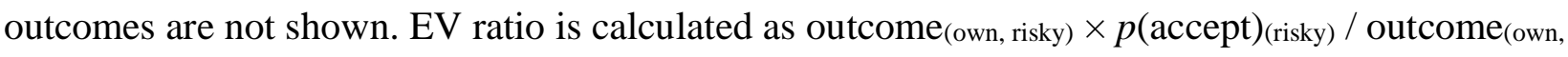
safe) $\times p(\text { accept })_{(\text {safe) }}$. The rightmost column categorizes situations by whether the safe option 
contains an equal split or an unequal allocation advantageous to the proposer or responder. Plus signs indicate the three decision situations added in Experiment 2.

Prior to making an offer, proposers could sample from two decks of cards representing the two allocations in question (options $\mathrm{X}$ and $\mathrm{Y}$; Figure 1) without costs, in any sequence, and as many times as they wanted. They were informed that the rejection rates they would experience reflected the choices of previous respondents drawn from the same population. Because the outcomes were not stated prior to sampling, all participants needed to sample, even if they were not interested in the relative frequency of the possible outcomes.

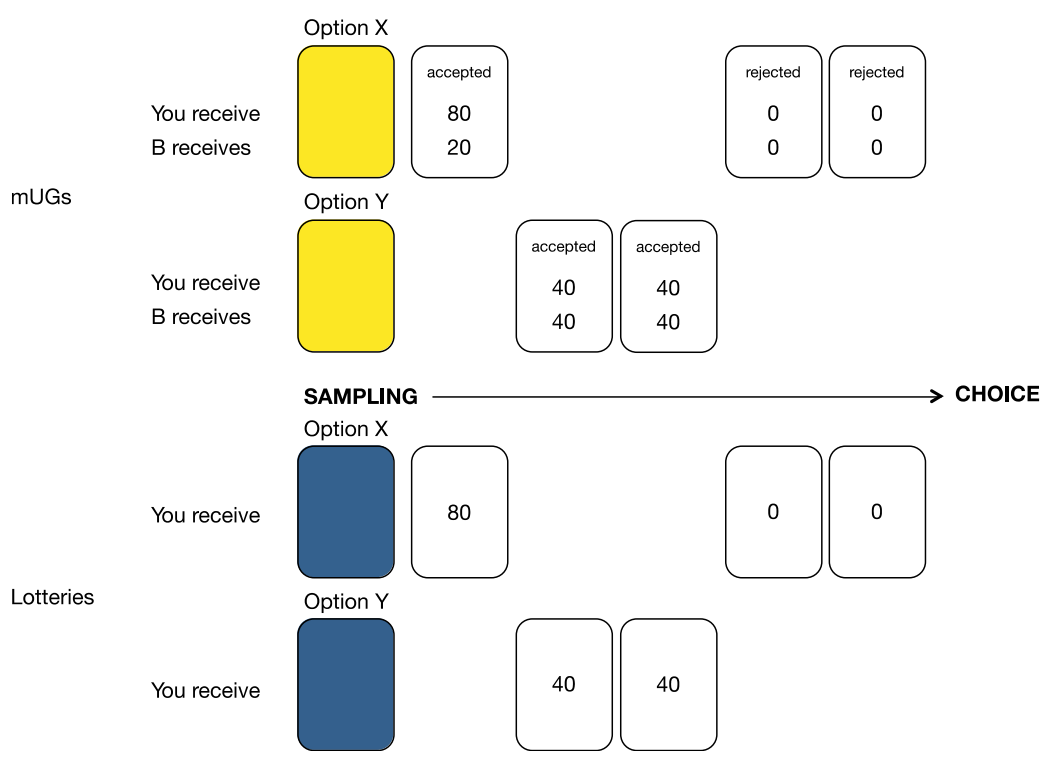

Figure 1.

Illustration of a sampling sequence in mUGs (top) and lotteries (bottom). Participants could sample from option X or Y by clicking on a card deck on the computer screen. Each time they clicked (in the example, five times), a card displayed an outcome drawn from the respective distribution.

When the participant clicked on a deck, a card was shown for $800 \mathrm{~ms}$ before being concealed again. Cards were randomly drawn with replacement from the empirical distribution of acceptances and rejections obtained in the preliminary study. Each card showed whether the offer was accepted or rejected (Figure 1). Cards that signaled acceptance also showed the resulting 
outcomes for proposer and responder; cards that signaled rejection showed the outcome 0 for both parties. In the lottery condition, cards only showed information about a player's own outcomes. Importantly, the probability with which outcomes occurred was identical to the distribution in the mUGs. Thus, the information that participants could sample about their own possible outcomes and probabilities of those outcomes was constant between conditions. When participants felt ready to make a decision, they clicked on a corresponding button and indicated their choice on the next screen.

To classify participants in mUGs according to their social motives, we used 12 minidictator games (mDGs) that presented the same allocations as in the mUGs. In the mDGs, however, the proposer faced no risk because the responder could not reject the 'dictated' allocation. To validate this classification, we additionally administered an established measure of social value orientation (SVO; Murphy, Ackermann, \& Handgraaf, 2011).

We further classified selfish individuals as risk-sensitive if they chose the more advantageous allocation for themselves in the majority of mDGs but shied away from it in the majority of mUGs, where the responder had the option to reject the offer. In addition, participants completed a classic measure of risk attitudes (Holt \& Laury, 2002).

\section{Procedures}

In total, participants sampled and made decisions in 12 situations without feedback (Table 1), either as a proposer choosing between two allocations or as a solitary player choosing between two lotteries. Proposers were randomly matched with a different player for each choice (for instructions, see the Supplemental Material). In the mUG condition, participants completed five tasks in total. First, they made the 12 choices as proposer. Before being allowed to begin, they had to correctly answer control questions about how the payoff was determined, followed by a test trial with feedback. Second, they took on the role of responder and stated for each situation whether they would accept or reject each of the two possible allocations ("strategy method"; Brandts \& Charness, 2011). Third, they made decisions in 12 mDGs with the same allocations as in the mUGs. Fourth and fifth, they completed the SVO measure (Murphy et al., 2011) and the risk attitude measure (Holt \& Laury, 2002). The tasks were always administered in this order. Within tasks, with the exception of the SVO and risk attitude measure, the order of decision situations and the screen position of options were randomized. In the lottery condition, 
participants completed two tasks: making 12 lottery choices (after a test trial with feedback) and the risk attitude measure.

Each participant was paid for one randomly drawn choice from each task in addition to a show-up fee of $€ 3$. Participants received $€ 1$ per 40 points earned in $m U G$ and $€ 1$ per 25 points earned in lotteries; this payment scheme resulted in about the same average hourly payment in both conditions. The experiment lasted approximately 60 minutes in the mUG condition and 30 minutes in the lottery condition. On average, participants earned $€ 13.10$ and $€ 7.40$, respectively.

\section{Results}

\section{Does sampling behavior differ between mUGs and lotteries?}

As expected, participants in mUGs sampled much less than participants in lotteries (Figure 2a). The median sample size in mUGs $(M d n=7.5, M=8.87, I Q R=4.67-10.06)$ was less than one-third of that in lotteries $(M d n=24.5, M=28.00, I Q R=15.71-38.27)$, a difference of 17 draws, $W(42,46)=249, p<.001, r=0.64 .^{1}$ The differing propensities to sample less were not learned across trials but were already manifest in the first choice that participants randomly encountered (mUGs: $M d n=12, M=13.21, I Q R=6.25-16.75$; lotteries: $M d n=26.5, M=33.98$, $I Q R=10-45.75, U(48,45)=560, p<.001, r=0.36$; see Figure A1 in the Appendix).

$\mathbf{a}$

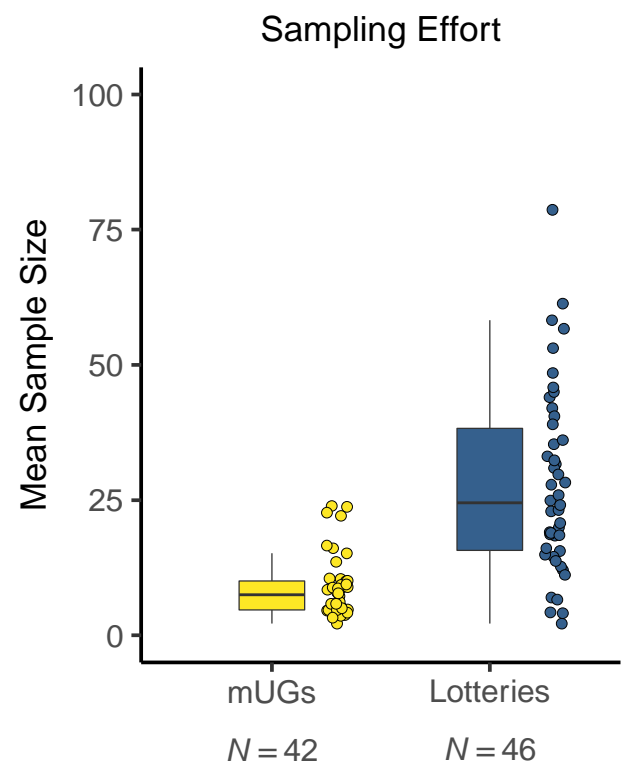

b

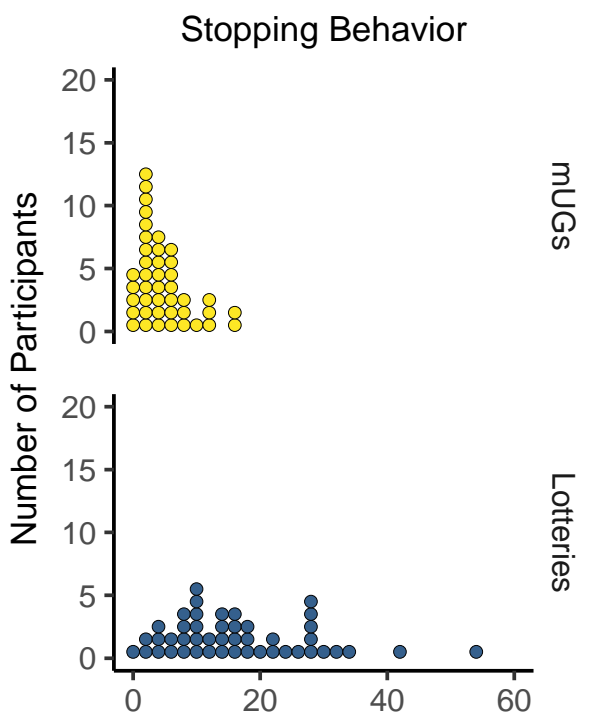

Samples after Seeing both Outcomes

Figure 2. Sample size (a) and stopping behavior (b) of participants across all decision

\footnotetext{
${ }^{1}$ We always first calculated the mean sample size per participant across all decision situations before aggregating across participants.
} 
situations in the mUG and lottery conditions in Experiment 1.

a. Distribution of participants' sample sizes. Each dot represents the mean of one participant across all choice situations. The distance between the lower and upper limit of the box shows the IQR of the distribution (distance between the 25th and 75th percentiles); the horizontal line represents the median. The upper (lower) whisker extends from the box to the highest (lowest) value within $1.5 *$ IQR.

b. Histogram of the number of samples drawn after the nonzero outcomes of both options were encountered. Each dot represents the mean of one participant across all decision situations.

We also took a closer look at how systematically participants sampled and when they stopped (Figure 2b). Specifically, we calculated how often a participant switched between options relative to the possible number of switches given the sample size $(n-1) .^{2}$ In lotteries, the switching ratio was quite low $(M d n=.07, M=.30, I Q R=0.05-0.50)$, indicating a systematic sampling strategy suited to separately evaluating the frequencies of the outcomes for each option (Hills \& Hertwig, 2010). In mUGs, in contrast, the switching ratio was higher despite the lower sample size $(M d n=.70, M=.64, I Q R=.50-.81) ; U(46,42)=422, p<.001, r=-.47$, indicating a more alternating strategy, suited to learning about the potential outcomes rather than their frequencies. Once participants had encountered the nonzero outcomes of both options, they stopped sampling after a median of 3.78 of draws in mUGs $(M=4.79, I Q R=1.92-6.13)$, relative to 14.25 draws in lotteries $(M=16.73, I Q R=9.13-23.77), U(42,46)=265, p<.001, r=.62$ (Figure 2b). They stopped immediately (or one card later) in a median of 4 out of 12 situations in mUGs $(M=3.93, I Q R=1.25-6)$ but almost never in lotteries $(M d n=0, M=0.80, I Q R=0-1)$, $U(42,46)=1616, p<.001, r=-.60$.

Overall, the observed differences in sample size, sampling strategy, and stopping behavior indicate that, under social uncertainty, people's sampling effort was targeted at finding out the potential allocations rather than the associated risk (probability) of rejection.

\section{Do even risk-sensitive selfish individuals sample less than players in lotteries?}

In order to achieve their goal of maximizing their own outcomes, risk-sensitive selfish individuals need to carefully gauge the empirical risk of rejection. Do they do so through

\footnotetext{
${ }^{2}$ If fewer than two samples were drawn, the switching ratio was set to 0 .
} 
sampling, in the same way as participants in lotteries, who share the goal of personal outcome maximization? We classified individuals as being selfish and risk-sensitive if they met two conditions: (i) they made the selfish choice in most of the 12 mDGs, where there was no risk of rejection, but (ii) shied away from that choice in most of the 12 mUGs, where the responder could potentially reject the offer, and instead applied an equity strategy. The equity strategy was defined as choosing the allocation that minimized the difference between the two parties' outcomes.

Individuals who behaved selfishly in most $\mathrm{mDGs}$ and $\mathrm{mUGs}$ were classified as selfish-rational; these individuals have no reason to sample to gauge the risk of rejection. Our results showed that even the group of selfish individuals who were ostensibly sensitive to the risk of rejection sampled as little as proposers with other motives $(M d n=7.83, M=10.52, I Q R=4.81-14.21$ versus $M d n=6.88, M=7.85, I Q R=4.60-9.23$; Figure 3), $U(16,26)=244, p>.250, r=.14$ and much less than individuals facing isomorphic risks in lotteries (Figure 3). More generally, sampling effort was low across all social motivations, as reflected in the very low variance in mUGs relative to the much larger variance in lotteries (Further details and a validation of the above classification as selfish and risk-sensitive that draws on the SVO measure are provided under Robustness of Classification of Risk-Sensitive Selfish Participants in the Appendix). Thus, even selfish individuals who aimed to maximize their personal outcomes did not use the opportunity to sample for free, but appeared to apply cognitive tools as a substitute for sampling to evaluate the risk of rejection.

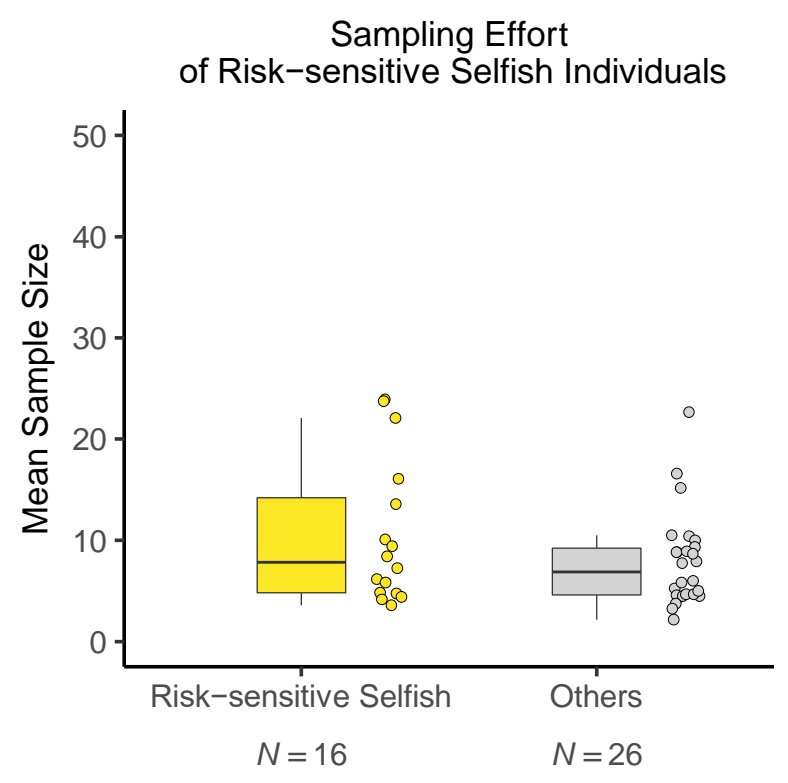


Figure 3. Distribution of participants' sample sizes in mUGs $(N=42)$, separately for risksensitive selfish participants and those with other motivations. The classification was based on the combination of participants' majority choices mUGs and mDGs. Each dot represents the mean sample size of one participant. The distance between the lower and upper limit of the box shows the IQR of the distribution; the horizontal line represents the median. The upper (lower) whisker extends from the box to the highest (lowest) value at $1.5 *$ IQR.

\section{Are risk attitude and sampling effort decoupled?}

The distributions of risk attitude did not differ between mUGs and lotteries (mUG: $M d n=$ $M=5, S D=1.89$; lotteries: $M d n=5, M=4.78, S D=2.16$ ). Thus, risk attitude cannot explain the observed differences in sampling effort. As predicted, individuals' risk attitudes did not correlate with their mean sample size in mUGs $\left(r_{s}=-.11, p>.250\right)$. Contrary to our expectation, however, there was no correlation in the lottery condition either $\left(r_{s}=-.20, p=.173\right)$. This means that, even in the lotteries, there was no direct link between individuals' attitude toward stated risk (i.e., known probabilities) and sampling effort with the goal of reducing uncertainty (i.e., unknown or vague probabilities). This result is in line with the findings of a recent study that found sampling effort to be correlated with individual ambiguity aversion but not with risk attitude (van den Bos \& Hertwig, 2017).

\section{Do choices in $m U G s$ and lotteries converge?}

Despite the notable differences observed in participants' sampling behavior in mUGs and lotteries, their actual choices were quite similar (Figure 4). The proportion of participants choosing the risky option in mUGs and lotteries was strongly correlated across the 12 choice situations $(r=.67, p=.018)$, with significant differences emerging for only two choice situations (no. 3 and 4; for detailed tests, see Table A1 in the Appendix). In both of these situations, the safe option presented an equal split, representing a normative focal point to respondents in mUGs despite its lower expected value and, at the same time, the alternative risky option presented a highly unequal split (which was not the case for situation no. 2 which also contained an equal split as the safe option). 


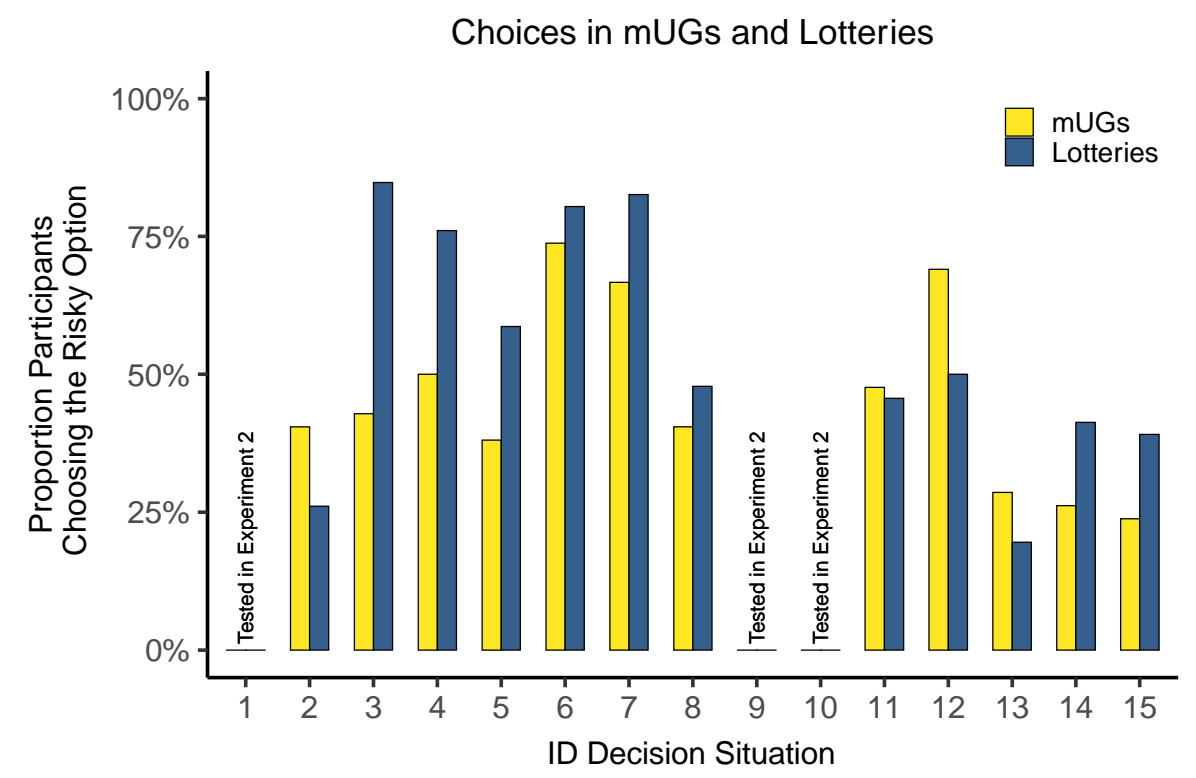

Figure 4. Percentage of participants choosing the risky option in mUGs and lotteries for the 12 decision situations in Experiment 1; for tests, see Table A1 in the Appendix. Choice situations are labeled by the ID used in Table 1 . Situations 1, 9, and 10 were included only in Experiment 2.

\section{Summary}

In line with the hypothesis that people enlist cognitive tools as a substitute for sampling to cope with social uncertainty, we found three differences in sampling behavior between conditions. Participants in mUGs sampled much less, followed an alternating sampling strategy that was suitable for finding out about all potential outcomes rather than their frequencies, and stopped sooner after experiencing all outcomes than did participants in lotteries. The differences provide converging evidence that, under social uncertainty, participants sampled not to learn about the risk of rejection but rather about the outcomes-which suffice to evaluate the risk of rejection through harnessing the cognitive tools of social projection or social norms. Even selfish proposers, who shared the motivation of players in lotteries to maximize their own personal outcomes, did not sample more to cope with social uncertainty. Individuals' attitude toward stated risk (i.e., known probabilities) was not linked to their sampling effort to reducing uncertainty (i.e., unknown or vague probabilities) in mUGs or lotteries and did not explain the differences in sampling effort between the two. Despite the differences in the size of the sample taken, choices were quite similar in both conditions - suggesting that perceptions of risk were also quite similar. 


\section{Experiment 2}

Experiment 2 tested three further implications of the hypothesis that people use cognitive tools as a substitute for sampling to cope with social uncertainty. Qualifying the hypotheses of Experiment 1, we tested whether the observed differences in sampling behavior between mUGs and lotteries hold under higher incentives, with anticipated sampling rather than actual sampling, and we tested an alternative hypothesis as to why choices are similar in both conditions. In addition, we replicated the differences in sampling behavior observed in Experiment 1 under stricter conditions.

\section{Is there a differential impact of incentives in $m U G$ s and lotteries?}

In lotteries, higher stakes have been found to prompt more sampling, presumably because people want to be more confident about outcome probabilities before making a decision (Hau et al., 2008; Hertwig \& Pleskac, 2010). In mUGs, in contrast, raising the stakes can be expected to have less impact on sampling effort, provided that cognitive tools such as social projection and norm-based expectation indeed allow decision makers to evaluate risks based on outcomes alone.

\section{Are there differences in anticipated sampling?}

When cognitive tools are applied, knowledge of the possible outcomes suffices to generate expectations about others' behavior. We can thus expect differences in anticipated sampling to be larger when the outcomes are public from the outset than when they have to be discovered through sampling. In addition, how much sampling participants in mUGs anticipate should vary depending on the perceived uncertainty of the situation. They should feel less need to sample allocations that unambiguously indicate norm violation or compliance (i.e., where the risk of rejection is unambiguously high or low) and more need to sample allocations for which normsand thus the risk of rejection - are more ambiguous. In lotteries, this connection should not hold.

\section{Do choices in mUGs and lotteries converge?}

Despite the marked differences observed in sampling effort, choices in mUGs and lotteries in Experiment 1 were quite similar, suggesting that cognitive tools enabled individuals to assess the risk without the need for exploration. Another possible explanation is that risk aversion, the prevalent risk attitude in lotteries (commonly defined as a preference for the option with lower outcome variance; Lejarraga, Hertwig, \& Gonzalez, 2012; Weber, Shafir, \& Blais, 2004) steered players toward the same option as implied by inequity aversion in social games (defined as a 
preference for the option that minimizes inequality). Although prompted by distinct preferences, inequity-averse and risk-averse individuals could thus favor the same choice.

\section{Methods}

\section{Participants}

Ninety-three students (48 women, 45 men; $M=25.39$ years) were recruited and assigned to one of the two conditions in the same way as in Experiment 1. To replicate the effect found in Experiment 1, the number of participants was again set at two sessions with 24 participants each per condition. A sample size of 48 per condition is sufficient to detect the effect observed in Experiment 1 with a power of .9 (power analysis, one-tailed Mann-Whitney $U$ test with $r=.64$ and $\alpha=.05)$.

\section{Experimental materials}

To investigate whether sampling effort remained low under social uncertainty even when incentives were higher, we increased the stakes and the importance of each decision by paying each participant for just one randomly drawn decision for each of three tasks (marked with an asterisk in the Procedures section below), in addition to a show-up fee of $€ 6$. Participants earned on average $€ 19.68$ in $m U G$ and $€ 18.90$ in lotteries. This payment scheme also prevented participants from distributing the risk ("hedging") over multiple choices (Thaler \& Johnson, 1990). In both conditions, the instructions explicitly stated that both options in each gamble had two possible outcomes, one of which was zero.

The incentive structure was now strictly identical in both conditions in terms of the number of tasks, study duration (approx. 90 minutes), and exchange rate (€1 per 3 points earned): it also allowed convergence in choice to be tested under stricter conditions than in Experiment 1.

We measured anticipated sampling by showing participants in both conditions the possible outcomes of both options for each situation and asking them to indicate how many samples they would take from each option if they had to make a choice.

Finally, we included three additional choice situations (no. 1, 9, and 10), resulting in five situations each in which the allocation of the "safe" option was equally beneficial to both participants, more beneficial to the proposer, or more beneficial to the responder (Table 1).

\section{Procedures}

The tasks in the $m U G$ condition were proposer choices*, responder choices*, an exploratory questionnaire, anticipated sample size judgments, and risk attitude*. The tasks in the 
lottery condition were lottery choices*, a filler task instead of responder choices*, an exploratory questionnaire, anticipated sample size judgments, and risk attitude*. ${ }^{3}$ All tasks were again administered in the same order, with the order of choice situations and screen position of the options being randomized within tasks, except for the risk attitude measure. Before being permitted to begin, participants in both conditions had to correctly answer control questions about how their payoff (as a proposer or lottery player) was determined, followed by a test trial with feedback.

\section{Results}

\section{Is there a differential impact of incentives in $m U G$ s and lotteries?}

Raising the stakes in Experiment 2 increased the difference in sampling effort between mUGs and lotteries. Figure 5a plots the distribution of sample size in mUGs $(M d n=11.20, M=$ $13.69, I Q R=7.6-16.57)$ and lotteries $(M d n=39.87, M=38.93, I Q R=23.73-51.67), W(48,45)=$ 266.5, $p<.001, r=-.65 .{ }^{4}$ Sample size increased strongly in lotteries but only weakly in mUGs. Relative to Experiment 1, where we observed a difference in sample size of 17 draws between the conditions, we now observed an even larger difference of about 29 draws. As in Experiment 1, the difference in sample size was already manifest in the first choice that participants randomly encountered (mUGs: $M d n=16, M=18.27, I Q R=8.5-26.2$; lotteries: $M d n=39, M=49.09$, $I Q R=22-67, U(48,45)=467.5, p<.001, r=0.49 ;$ Figure A1).

Despite the increased incentives relative to Experiment 1, the differences observed in sampling strategy and stopping behavior remained, indicating that people sampled to learn about probabilities in lotteries but about outcomes in mUGs. Lottery participants sampled each option comprehensively without much switching $(M d n=.05, M=.15, I Q R=.03-.10)$, whereas mUGs participants switched often given their low sample size $(M d n=.30, M=.42, I Q R=.16-.65)$, comparing the potential outcomes of the two options rather than their frequency, $U(45,48)=$ $295.5, p<.001, r=-.63$. Once participants had encountered the nonzero outcomes of both options, they stopped sampling after a median of just 5.52 draws in mUGs $(M=8.24, I Q R=$ 3.76-10.47), relative to 20.67 draws in lotteries $(M=21.36, I Q R=11.47-28.67), U(48,45)=376$, $p<.001, r=-.56$ (Figure 5b). They even stopped immediately (or one card later) in a median of

\footnotetext{
${ }^{3}$ The questionnaire and filler task are not relevant to the present analysis and their results are not reported.

${ }^{4}$ For all analyses of actual and anticipated sampling, we again first calculated the mean sample size per participant across all decision situations before aggregating across participants.
} 
2.5 out of 15 situations in mUGs $(M=3.17, I Q R=0-5)$ but not in lotteries $(M d n=0, M=.62$, $I Q R=0-0), U(48,45)=1662.5, p<.001, r=.51$.

As in Experiment 1, sampling effort was uncorrelated with risk attitude in mUGs $\left(r_{s}=\right.$ $-.25, p=.092)$ or lotteries $\left(r_{s}=-.22, p=.154\right)$.

$\mathbf{a}$

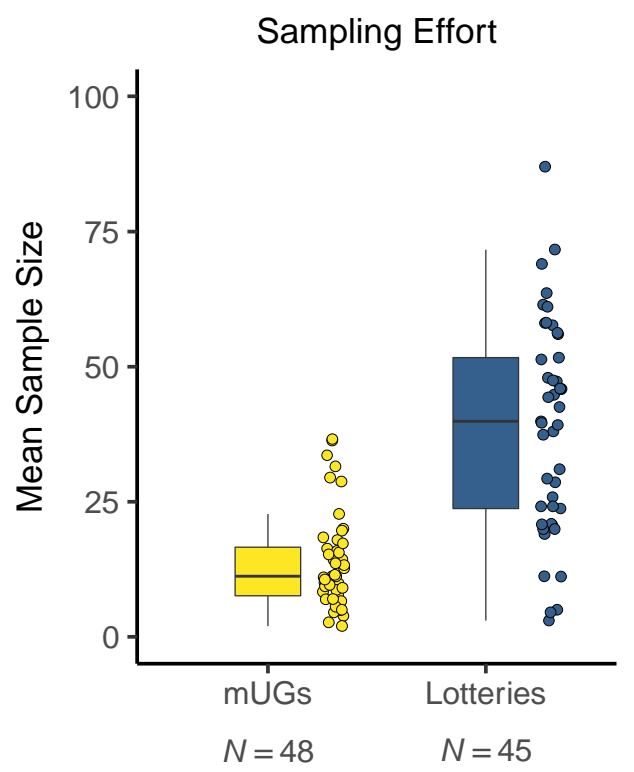

$\mathbf{b}$

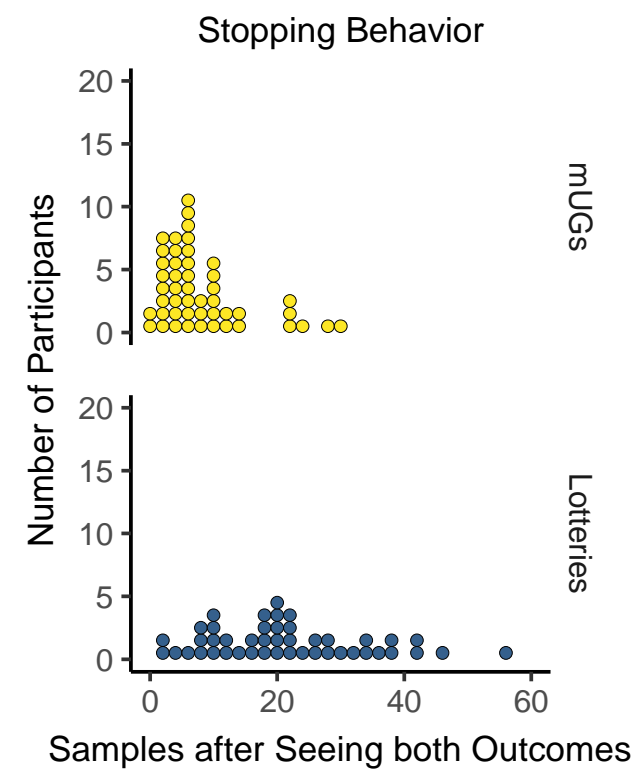

Figure 5. Sample size (a) and stopping behavior (b) of participants across all decision situations in the mUG and lottery conditions in Experiment 2.

a. Distribution of participants' sample sizes. Each dot represents the mean of one participant across all choice situations. The distance between the lower and upper limit of the box shows the IQR of the distribution; the horizontal line represents the median. The upper (lower) whisker extends from the box to the highest (lowest) value within $1.5 * \mathrm{IQR}$.

b. Histogram of the number of samples drawn after the nonzero outcomes of both options were encountered. Each dot represents the mean of one participant across all decision situations.

\section{Are there differences in anticipated sampling?}

The difference in anticipated sampling was even stronger than that observed in actual sampling: Anticipated sample size was much lower in mUGs $(M d n=8.63, M=10.26, I Q R=$ 5.93-12.98) than in lotteries $(M d n=40, M=44, I Q R=24.33-54.67), U(48,45)=132.5, p$ $<.001, r=-.76$. 
To test whether participants in mUGs anticipated sampling less for allocations that unambiguously indicated norm violation or compliance than for allocations that were normatively more ambiguous, we used the size of the responder outcome in the risky option as a simple proxy for the norm. The higher the responder outcome, the lower the risk of rejection in mUGs $\left(r_{s}=\right.$ $-.60, p=.017)$. If the perceived uncertainty varies as a function of the normative ambiguity of the allocations, we would expect to observe an inverse U-shaped relation: Participants should anticipate sampling less if the responder outcome is either low (high risk of rejection) or high (low risk of rejection) and sampling more if the responder outcome (and risk) is intermediate. This is indeed what we found. A model with a quadratic term for responder outcome fitted the data better than a linear model (linear mixed model with responder outcome as a fixed effect and intercepts for participants as random effects, $X^{2}(1)=38.76, p<.001$, likelihood ratio test). For lotteries, in contrast, the quadratic model, based on the player's own outcome, did not predict the anticipated sample size for the risky option any better than a linear model. At the same time, 29\% of participants in lotteries anticipated searching uniformly across all situations, relative to just $2 \%$ in mUGs, suggesting that lottery participants did not extract information about risk from outcomes.

\section{Do choices in mUGs and lotteries converge?}

Although the differences in sampling effort between mUGs and lotteries were even larger than in Experiment 1, participants' choices showed even greater convergence. Across the 15 choice situations, we observed a substantial correlation $\left(r_{s}=.80, p<.001\right.$; Figure 6$)$; choices differed significantly in only one situation (no. 1; difference of $35 \%$ ), $X^{2}(1, N=93$ ) $=10.25, p$ $=.001, \phi=.33,95 \% \mathrm{CI}[14,56]$ (see Table $\mathrm{A} 2$ in the Appendix). In both experiments, differences occurred only in situations where the safe option offered an equal split, representing a normative focal point to respondents in mUGs despite its lower expected value and, at the same time, the risky option was a highly unequal split (which was not the case for situations no. 1 or 2 which also contained an equal split as the safe option). 


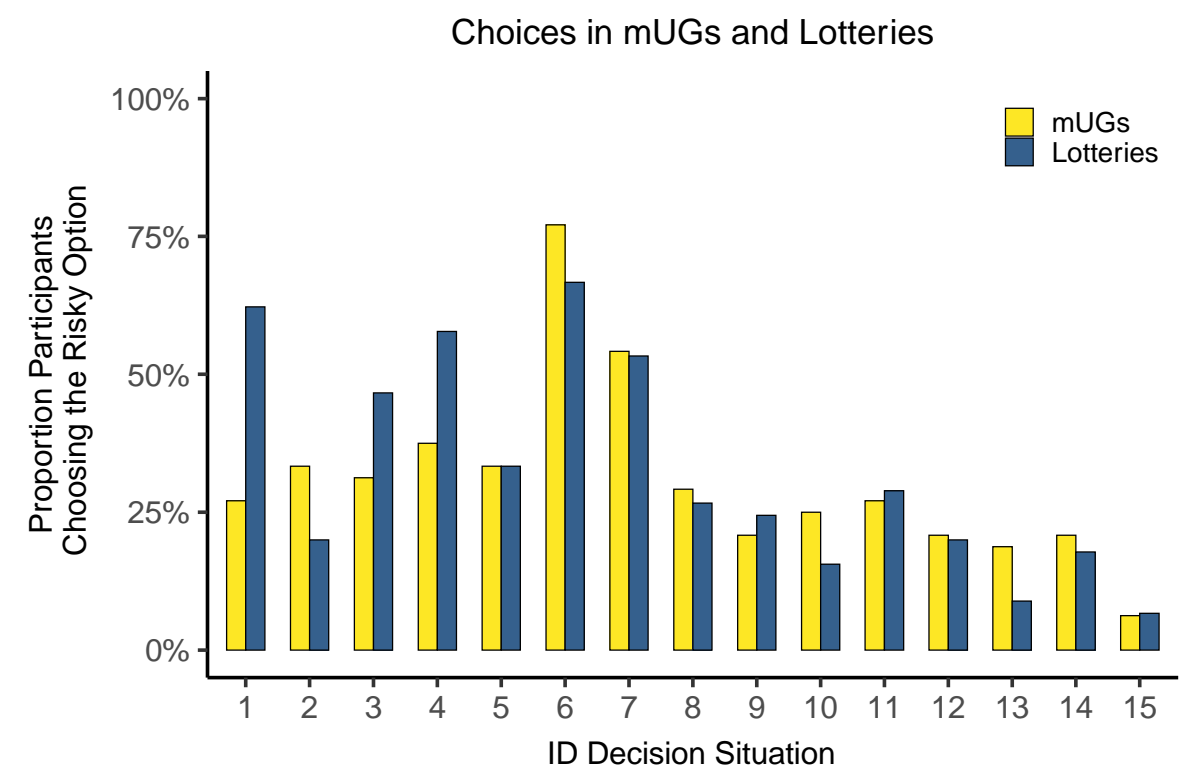

Figure 6. Percentage of participants choosing the risky option in mUGs and lotteries for the 15 decision situations in Experiment 2; for tests, see Table A2 in the Appendix. Choice situations are labeled by the ID used in Table 1.

Why did choices converge despite the differences in sampling effort? Overall, the strong similarity in choices across both conditions suggests that perceptions of risk were also similar. We can rule out the alternative explanation that choices were similar because participants in both conditions were simply indifferent to the probability information obtained through sampling. If participants in lotteries sampled to learn about the probabilities, the experienced frequencies should inform their choice; this should not be the case for participants in mUGs if they sampled to learn about outcomes only. Using the frequencies experienced in each situation, we therefore calculated how often each participant chose the option with the lower variance (a common riskaverse attitude in lotteries; Lejarraga et al., 2012). We found that the more participants sampled, the more likely they were to choose the option with the lower experienced variance in lotteries $\left(r_{s}\right.$ $=.51, p<.001)$ but not in mUGs $\left(r_{s}=.05 p>.250\right) .{ }^{5}$ This result further supports the notion that experienced frequencies informed choice in lotteries but not in mUGs, where cognitive tools can be used as a substitute for sampling to evaluate risk.

\footnotetext{
${ }^{5}$ The analysis includes all cases where the variance model could make a prediction - that is, where both options were sampled at least once and did not have the same experienced variance. This excluded $10 \%$ of all decisions of all participants in lotteries, relative to $31 \%$ of the decisions of all participants in mUGs, reflecting the much lower sample size. If only one sample was drawn from an option, its variance was set to zero.
} 
Another possible explanation for the convergence of choices in mUGs and lotteries is that people may choose the option with the lower outcome variance for different reasons - namely, risk aversion (a nonsocial preference) in lotteries and inequity aversion (a social preference) in mUGs. To explore this possibility, we used the experienced frequencies of each participant and situation in lotteries to calculate the lower variance option, and compared how often this option coincided with the more equitable option in mUGs. Based on the experienced frequencies in lotteries, a model choosing the lower experienced variance option in lotteries would in fact predict the same option as a model choosing the more equitable option in mUGs in $92 \%$ of all decisions. ${ }^{6}$ Thus, people behaved similarly in both conditions - although perhaps for different reasons.

\section{Summary}

Raising the stakes boosted sampling efforts in lotteries but not in mUGs. Despite higher incentives, participants in mUGs again sampled only to learn about the outcomes and not about their probabilities. When outcomes were public from the outset, the difference in anticipated sample size was even larger. Moreover, participants in mUGs anticipated sampling less for allocations that clearly indicated normative behavior, suggesting that they extracted information about risk from outcomes. Although sampling behavior differed markedly between conditions, choices converged. A closer look revealed that experienced probabilities mattered more for choice in lotteries than in mUGs, where participants could harness cognitive tools to cope with uncertainty.

\section{Discussion}

The social world is often depicted as more uncertain than the nonsocial world. Nevertheless, we have argued, if the environment affords the use of cognitive tools that allow risk to be evaluated based on knowledge of outcomes alone, people are less likely to sample in order to cope with uncertainty. In support of this hypothesis, we found three major differences in sampling behavior between the social environment and an environment where uncertainty results from a chance mechanism.

First, in the social environment (mini-ultimatum games), participants sampled considerably less than in the nonsocial environment (lotteries), used an alternating sampling strategy better suited to learning about potential outcomes than their frequencies, and stopped

\footnotetext{
${ }^{6}$ This excludes the $10 \%$ of decisions for which the low variance model made no prediction.
} 
sampling quickly once all outcomes had been observed. Even selfish individuals sensitive to the risk of rejection did not sample more than others, let alone as much as people in lotteries. Second, raising the stakes strongly increased sampling effort in lotteries but not in mUGs. Third, based on outcomes alone, participants anticipated searching less in mUGs than in lotteries - and least of all in situations where the allocation clearly indicated norm violation or compliance, indicating that they extracted information from outcomes to generate expectations.

One way to interpret these results is that people have an adaptive toolbox of cognitive tools, including the exploration of the environment, that they can use flexibly to deal with uncertainty (Hertwig, Pleskac, Pachur \& The Center for Adaptive Rationality, 2019). One may speculate that exploring the environment through sampling is time consuming and effortful, and that other tools may attenuate the opportunity and cognitive costs of information search, rendering them preferable when available. The present studies were intended to examine and document theoretically and practically interesting differences in the way people cope with uncertainty between social games and games against nature; however, they cannot provide insights into the cognitive mechanisms behind the results. Investigating which cognitive tools individuals apply and under which conditions is a promising avenue for future research.

Do social worlds always entail less exploration than nonsocial worlds? The perceived need for exploration likely depends on the structure of the environment (Pirolli \& Card, 1999). Exploration may increase as one's own behavior or social norms become less valid as predictors of behavior - for example, when injunctive and descriptive norms (Cialdini et al., 1991) conflict; when conflicting injunctive norms imply opposite behaviors; or when a social domain is not (yet) governed by norms. Yet it may decrease under competition (Phillips, Hertwig, Kareev, \& Avrahami, 2014). Even lotteries can offer environmental regularities (Pleskac, Conradt, Leuker, \& Hertwig, 2020; Pleskac \& Hertwig, 2014) that may reduce the need for exploration. If people have even stronger expectations about the likelihood of possible outcomes based on their causal models of the physical world (Meder, Mayrhofer, \& Waldmann, 2014), exploration may be curtailed.

Even if the social and nonsocial worlds differ in their degree of uncertainty, this does not mean that the mind perceives and treats them accordingly. The key psychological question is which cognitive tools and environmental structures the mind can enlist to navigate uncertainty. In social worlds, it is possible to exploit the fact that people are not dispassionate random devices 
whose behavioral propensities are revealed only through extensive exploration. Instead, social worlds embody norm-based probabilistic structures that render the behavior of others predictable. These structures afford the application of cognitive tools and thus obviate the need for extensive exploration. 


\section{Data Availability}

All code, materials and data that support the findings of this study are openly available at the Open Science Framework at https://osf.io/hc3rq/.

\section{Acknowledgements}

We thank Judith Avrahami, Yaakov Kareev, Björn Meder, and Leonidas Spiliopoulos for feedback, and Susannah Goss for editing. This research was funded by the Max Planck Institute for Human Development, Berlin, Germany. It did not receive any specific grants from funding agencies in the public, commercial, or not-for-profit sectors.

\section{Author Contributions}

N. F. designed the experiments, collected data, performed data analysis, and wrote the manuscript. F. A. designed the experiments, collected data, and provided critical revisions. S. O. designed the experiments, collected data, and verified the data analysis. R. H. designed the experiments and provided critical revisions. 


\section{References}

Artinger, F., Exadaktylos, F., Koppel, H., \& Sääksvuori, L. (2014). In others' shoes: Do individual differences in empathy and theory of mind shape social preferences? PLOS ONE, 9, e92844. doi:10.1371/journal.pone.0092844

Bacharach, M., \& Bernasconi, M. (1997). The variable frame theory of focal points: An experimental study. Games and Economic Behavior, 19, 1-45. doi:10.1006/game.1997.0546

Bicchieri, C., \& Chavez, A. (2009). Behaving as expected: Public information and fairness norms. Journal of Behavioral Decision Making, 23, 161-178. doi:10.1002/bdm.648

Blanco, M., Engelmann, D., \& Normann, H. T. (2011). A within-subject analysis of otherregarding preferences. Games and Economic Behavior, 72, 321-338. doi:10.1016/j.geb.2010.09.008

Bolton, G. E., \& Zwick, R. (1995). Anonymity versus punishment in ultimatum bargaining. Games and Economic Behavior, 10, 95-121. doi:10.1006/game.1995.1026

Brandts, J., \& Charness, G. (2011). The strategy versus the direct-response method: A first survey of experimental comparisons. Experimental Economics, 14, 375-399. doi:10.1007/s10683011-9272-X

Byrne, R. W., \& Whiten, A. (1988). Machiavellian intelligence: Social expertise and the evolution of intellect in monkeys, apes, and humans. Oxford, United Kingdom: Clarendon Press.

Carpenter, J. P. (2003). Bargaining outcomes as the result of coordinated expectations: An experimental study of sequential bargaining. Journal of Conflict Resolution, 47, 119-139. doi:10.1177/0022002702251023

Cialdini, R. B., Kallgren, C. A., \& Reno, R. R. (1991). A focus theory of normative conduct: A theoretical refinement and reevaluation of the role of norms in human behavior. In M. P. Zanna (Ed.), Advances in experimental social psychology (Vol. 24, pp. 201-234). San Diego, CA: Academic Press.

Costa-Gomes, M., Crawford, V. P., \& Broseta, B. (2001). Cognition and behavior in normal-form games: An experimental study. Econometrica, 69, 1193-1235. doi:10.1111/14680262.00239

Denrell, J., \& Le Mens, G. (2007). Interdependent sampling and social influence. Psychological 
Review, 114, 398-422. doi:10.1037/0033-295X.114.2.398

Fehr, E., \& Schmidt, K. M. (1999). A theory of fairness, competition, and cooperation. The Quarterly Journal of Economics, 114, 817-868. doi:10.1162/003355399556151

Fischbacher, U. (2007). Z-tree: Zurich toolbox for ready-made economic experiments. Experimental Economics, 10, 171-178. doi:10.1007/s10683-006-9159-4

Fiske, S. T., \& Taylor, S. E. (1984). Social cognition. New York, NY: Random House.

Güth, W., Schmittberger, R., \& Schwarze, B. (1982). An experimental analysis of ultimatum bargaining. Journal of Economic Behavior \& Organization, 3, 367-388. doi:10.1016/01672681(82)90011-7

Harrison, G. W., \& McCabe, K. A. (1996). Expectations and fairness in a simple bargaining experiment. International Journal of Game Theory, 25, 303-327. doi:10.1007/BF02425260

Hau, R., Pleskac, T. J., Kiefer, J., \& Hertwig, R. (2008). The description-experience gap in risky choice: The role of sample size and experienced probabilities. Journal of Behavioral Decision Making, 21, 493-518. doi:10.1002/bdm.598

Hertwig, R., \& Erev, I. (2009). The description-experience gap in risky choice. Trends in Cognitive Sciences, 13(12), 517-523. doi:10.1016/j.tics.2009.09.004

Hertwig, R., \& Herzog, S. M. (2009). Fast and frugal heuristics: Tools of social rationality. Social Cognition, 27(5), 661-698. doi:10.1521/soco.2009.27.5.661

Hertwig, R., \& Pleskac, T. J. (2010). Decisions from experience: Why small samples? Cognition, 115(2), 225-237. doi:10.1016/j.cognition.2009.12.009

Hertwig, R., Pleskac, T. J., Pachur, T., \& The Center for Adaptive Rationality (2019). Taming uncertainty. Cambridge, MA: MIT Press.

Hertwig, R., \& Volz, K. G. (2013). Abnormality, rationality, and sanity. Trends in Cognitive Sciences, 17, 547-549. doi:10.1016/j.tics.2013.08.011

Hills, T. T., \& Hertwig, R. (2010). Information search in decisions from experience: Do our patterns of sampling foreshadow our decisions? Psychological Science, 21, 1787-1792. doi:10.1177/0956797610387443

Holt, C. A., \& Laury, S. K. (2002). Risk aversion and incentive effects. American Economic Review, 92, 1644-1655. doi:10.1257/000282802762024700

Humphrey, N. K. (1988). The social function of intellect. In R. Byrne \& A. Whiten (Eds.), Machiavellian intelligence: Social expertise and the evolution of intellect in monkeys, apes, 
and humans (pp. 13-26). Oxford, United Kingdom: Clarendon Press.

Krueger, J. I., DiDonato, T. E., \& Freestone, D. (2012). Social projection can solve social dilemmas. Psychological Inquiry, 23(1), 1-27. doi:10.1080/1047840X.2012.641167

Lejarraga, T., Hertwig, R., \& Gonzalez, C. (2012). How choice ecology influences search in decisions from experience. Cognition, 124, 334-342. doi:10.1016/j.cognition.2012.06.002

Meder, B., Mayrhofer, R., \& Waldmann, M. R. (2014). Structure induction in diagnostic causal reasoning. Psychological Review, 121, 277-301. doi:10.1037/a0035944

Mill, W., \& Theelen, M. (2019). Social value orientation and group size uncertainty in public good dilemmas. Journal of Behavioral and Experimental Economics, 81, 19-38. doi:10.1016/j.socec.2019.05.001

Murphy, R., Ackermann, K., \& Handgraaf, M. (2011). Measuring social value orientation. Judgment and Decision Making, 6, 771-781. doi:10.2139/ssrn.1804189

Olschewski, S., Dietsch, M., \& Ludvig, E. A. (2019). Anti-social motives explain increased risk aversion for others in decisions from experience. Judgment and Decision Making, 14, 5871.

Phillips, N. D., Hertwig, R., Kareev, Y., \& Avrahami, J. (2014). Rivals in the dark: How competition influences search in decisions under uncertainty. Cognition, 133, 104-119. doi:10.1016/j.cognition.2014.06.006

Pirolli, P., \& Card, S. (1999). Information foraging. Psychological Review, 106, 643-675. doi:10.1037/0033-295X.106.4.643

Pleskac, T. J., Conradt, L., Leuker, C., \& Hertwig, R. (2020). The ecology of competition: A theory of risk-reward environments in adaptive decision making. Psychological Review. Advance online publication. doi:10.1037/rev0000261

Pleskac, T. J., \& Hertwig, R. (2014). Ecologically rational choice and the structure of the environment. Journal of Experimental Psychology: General, 143, 2000-2019. doi:10.1037/xge0000013

Rand, D. G., Peysakhovich, A., Kraft-Todd, G. T., Newman, G. E., Wurzbacher, O., Nowak, M. A., \& Greene, J. D. (2014). Social heuristics shape intuitive cooperation. Nature Communications, 5: 3677. doi:10.1038/ncomms4677

Sterelny, K. (2003). Thought in a hostile world: The evolution of human cognition. Oxford, United Kingdom: Blackwell. 
Thaler, R. H., \& Johnson, E. J. (1990). Gambling with the house money and trying to break even: The effects of prior outcomes on risky choice. Management Science, 36, 643-660. doi:10.1287/mnsc.36.6.643

van den Bos, W., \& Hertwig, R. (2017). Adolescents display distinctive tolerance to ambiguity and to uncertainty during risky decision making. Scientific Reports, 7:40962. doi:10.1038/srep40962

Volz, K. G., \& Hertwig, R. (2016). Emotions and decisions beyond conceptual vagueness and the rationality muddle. Perspectives on Psychological Science, 11, 101-116. doi:10.1177/1745691615619608.

Weber, E. U., Shafir, S., \& Blais, A. R. (2004). Predicting risk sensitivity in humans and lower animals: Risk as variance or coefficient of variation. Psychological Review, 111, 430-445. doi:10.1037/0033-295X.111.2.430

Wulff, D. U., Hills, T. T., \& Hertwig, R. (2015). How short- and long-run aspirations impact search and choice in decisions from experience. Cognition, 144, 29-37. doi:10.1016/j.cognition.2015.07.006. 


\section{Appendix}

Table A1. Percentage of Participants Choosing the Risky Option by Condition in Experiment 1

\begin{tabular}{|c|c|c|c|c|c|c|c|c|}
\hline \multirow{2}{*}{ Situation } & \multirow{2}{*}{$\begin{array}{l}\text { mUG } \\
n=42\end{array}$} & \multirow{2}{*}{$\begin{array}{l}\text { Lottery } \\
n=46\end{array}$} & \multirow{2}{*}{ Difference } & \multicolumn{2}{|c|}{$95 \% \mathrm{CI}$} & \multirow{2}{*}{$\begin{array}{c}X^{2} \\
(1, N=88)\end{array}$} & \multirow[t]{2}{*}{$p$} & \multirow{2}{*}{$\begin{array}{c}\text { Effect size } \\
\qquad(\phi)\end{array}$} \\
\hline & & & & $L L$ & $U L$ & & & \\
\hline $1^{+}$ & - & - & - & - & - & - & - & - \\
\hline 2 & 40 & 26 & 14 & -7 & 36 & 1.46 & 0.227 & 0.13 \\
\hline 3 & 43 & 85 & -42 & -62 & -21 & 15.13 & $<.001$ & 0.41 \\
\hline 4 & 50 & 76 & -26 & -48 & -4 & 5.38 & 0.020 & 0.25 \\
\hline 5 & 38 & 59 & -21 & -43 & 2 & 2.95 & 0.086 & 0.18 \\
\hline 6 & 74 & 80 & -6 & -26 & 13 & 0.24 & $>.250$ & 0.05 \\
\hline 7 & 67 & 83 & -16 & -36 & 4 & 2.19 & 0.139 & 0.16 \\
\hline 8 & 40 & 48 & -8 & -30 & 16 & 0.23 & $>.250$ & 0.05 \\
\hline $9^{+}$ & - & - & - & - & - & - & - & - \\
\hline $10^{+}$ & - & - & - & - & - & - & - & - \\
\hline 11 & 48 & 46 & 2 & -21 & 25 & 0.00 & $>.250$ & 0.00 \\
\hline 12 & 69 & 50 & 19 & -3 & 41 & 2.55 & 0.110 & 0.17 \\
\hline 13 & 29 & 20 & 9 & -11 & 29 & 0.55 & $>.250$ & 0.08 \\
\hline 14 & 26 & 41 & -15 & -37 & 7 & 1.61 & 0.204 & 0.14 \\
\hline 15 & 24 & 39 & -15 & -37 & 6 & 1.72 & 0.189 & 0.14 \\
\hline
\end{tabular}

Note: ${ }^{+}$Situations tested only in Experiment 2. 
Table A2. Percentage of Participants Choosing the Risky Option by Condition in Experiment 2

\begin{tabular}{|c|c|c|c|c|c|c|c|c|}
\hline \multirow{2}{*}{ Situation } & \multirow{2}{*}{$\begin{array}{c}\mathrm{mUG} \\
n=48\end{array}$} & \multirow{2}{*}{$\begin{array}{l}\text { Lottery } \\
n=45\end{array}$} & \multirow{2}{*}{ Difference } & \multicolumn{2}{|c|}{$95 \% \mathrm{CI}$} & \multirow{2}{*}{$\begin{array}{c}X^{2} \\
(1, N=93)\end{array}$} & \multirow[t]{2}{*}{$p$} & \multirow{2}{*}{$\begin{array}{c}\text { Effect size } \\
(\phi)\end{array}$} \\
\hline & & & & $L L$ & $U L$ & & & \\
\hline $1^{+}$ & 27 & 62 & -35 & -56 & -14 & 10.25 & 0.001 & 0.33 \\
\hline 2 & 33 & 20 & 13 & -7 & 33 & 1.48 & 0.224 & 0.13 \\
\hline 3 & 31 & 47 & -16 & -37 & 6 & 1.72 & 0.189 & 0.14 \\
\hline 4 & 38 & 58 & -20 & -42 & 2 & 3.06 & 0.080 & 0.18 \\
\hline 5 & 33 & 33 & 0 & -19 & 19 & 0.00 & $>.250$ & 0.00 \\
\hline 6 & 77 & 67 & 10 & -10 & 31 & 0.79 & $>.250$ & 0.09 \\
\hline 7 & 54 & 53 & 1 & -20 & 22 & 0.00 & $>.250$ & 0.00 \\
\hline 8 & 29 & 27 & 2 & -18 & 23 & 0.00 & $>.250$ & 0.00 \\
\hline $9^{+}$ & 21 & 24 & -3 & -23 & 16 & 0.03 & $>.250$ & 0.02 \\
\hline $10^{+}$ & 25 & 16 & 9 & -9 & 28 & 0.76 & $>.250$ & 0.09 \\
\hline 11 & 27 & 29 & -2 & -22 & 18 & 0.00 & $>.250$ & 0.00 \\
\hline 12 & 21 & 20 & 1 & -16 & 18 & 0.00 & $>.250$ & 0.00 \\
\hline 13 & 19 & 9 & 10 & -6 & 26 & 1.15 & $>.250$ & 0.11 \\
\hline 14 & 21 & 18 & 3 & -15 & 21 & 0.01 & $>.250$ & 0.01 \\
\hline 15 & 6 & 7 & -1 & -11 & 10 & 0.00 & $>.250$ & 0.00 \\
\hline
\end{tabular}

Note: ${ }^{+}$Situations tested only in Experiment 2. 
a

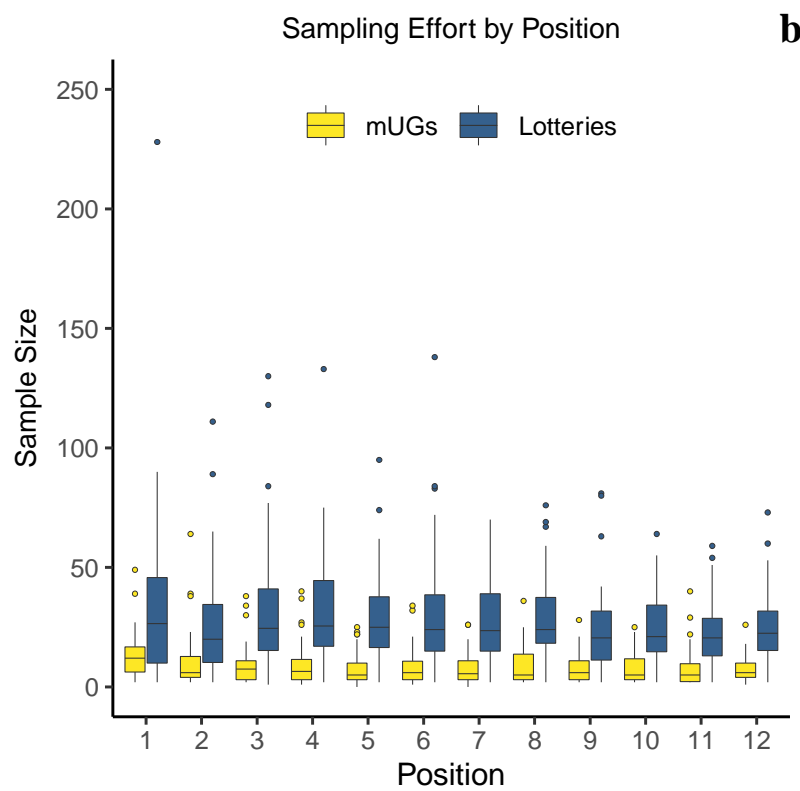

b

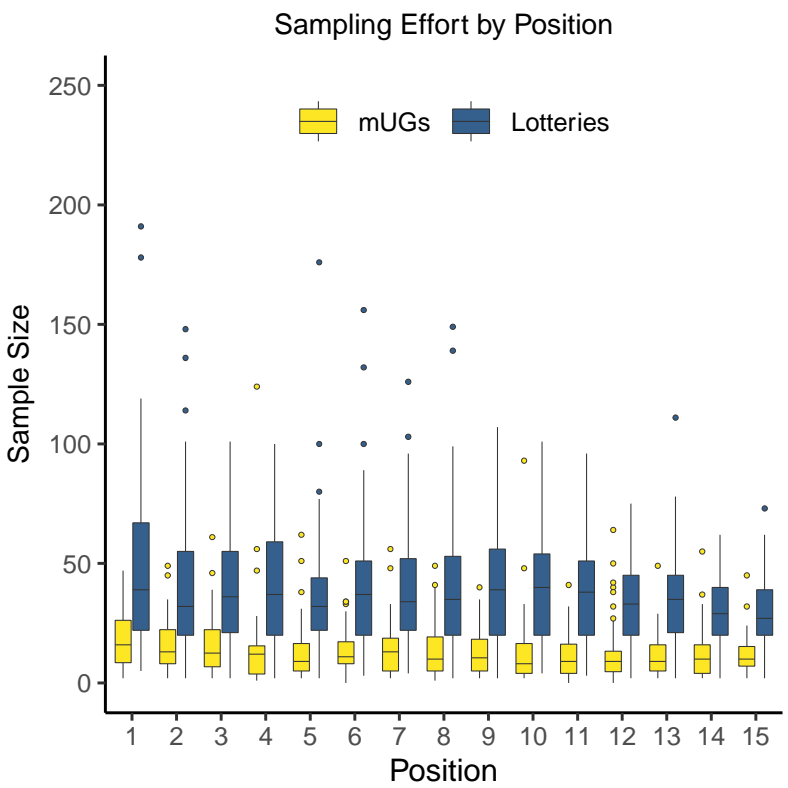

Figure A1. Boxplots of participants' sample sizes for decision situations in the order they were randomly encountered in the mUG and lottery conditions in Experiment 1 (a) and Experiment 2 (b). The distance between the lower and upper limit of the box shows the IQR of the distribution; the horizontal line represents the median. The upper (lower) whisker extends from the box to the highest (lowest) value within $1.5 *$ IQR. Dots outside represent outliers beyond this range. 


\section{Robustness of Classification of Risk-Sensitive Selfish Participants}

Participants were classified selfish and risk-sensitive if they (i) made the selfish choice in most mDGs, where there was no risk of rejection, but (ii) shied away from the same choice in most mUGs, where the responder could potentially reject the offer. To check the robustness of our classification of their social motives, we validated criterion (i) by comparing it with the classification made on the basis of an established social value orientation (SVO) measure (Murphy et al., 2011). The SVO measure consists of continuous dictator games designed to distinguish between selfish individualism and the prosocial concerns of altruism, social welfare, and equality. Correspondingly, in the classification based on mDGs, we distinguished between a selfish strategy (choosing the option most advantageous for oneself), a kind strategy (choosing the option most advantageous for the responder), a social welfare strategy (choosing the option with the highest sum of outcomes), and an equity strategy (choosing the option that minimizes the difference in outcomes between the two parties). Because the kind $(n=0)$ and social welfare strategy $(n=3)$ were very rare, we only used the selfish and equity strategies in the final analysis, comparing them with the selfish and prosocial classifications in the SVO.

The SVO classifications were identical to the classifications based on mDGs for $81 \%$ of the participants. Importantly, of the 23 people classified as selfish by the SVO, the mDGs identified 22. In addition, the mDGs classified seven further individuals as selfish-likely because the mDGs entail a more extreme trade-off between one's own benefit and the other person's benefit than do the continuous dictator games used in the SVO measure. Thus, prosocial behavior comes at a higher price in mDGs - allowing better comparison with mUGs, which entail the same binary choice situations. However, it is also possible that some individuals with prosocial motives considered it fair in some situations to choose more for themselves in mDGs after having been particularly generous and allocating more to the responder than to themselves in those situations in mUGs.

Importantly, when we instead classified risk-sensitive selfish participants as those who (i) were categorized as selfish according to the SVO measure, but (ii) employed the equity strategy in most situations in the mUG, this group still did not sample more $(M d n=5.83, M=$ $10.23, I Q R=4.58-15.75])$ than other proposers $(M d n=7.92, M=8.39, I Q R=4.67-10.04), U(11$, $\left.31)=164, p>.250, r_{s}=-.03\right)$. 